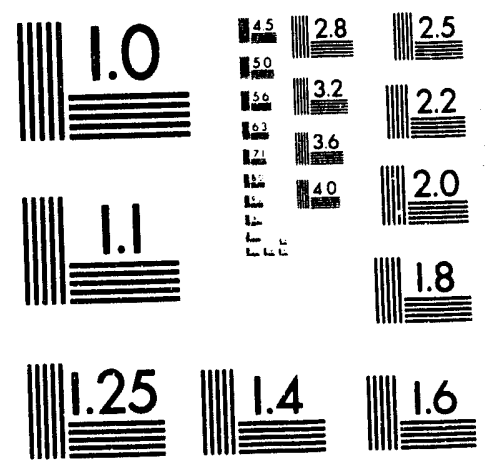





$$
\begin{aligned}
& \text { SAM:- } 9.3-16.7 \% \\
& \text { Co. } 4.930616-29
\end{aligned}
$$

\title{
OPTICALLY CONTROLLED CURRENT FILAMENTATION IN GaAs PHOTOCONDUCTIVE SEMICONDUCTOR SWITCHES*
}

\author{
F. J. Zutavern, A. Baca, W. D. Helgeson, H. P. Hjalmarson, \\ G. M. Loubriel, D. L. McLaughlin, M. W. O'Malley \\ Sandia National Laboratories, Albuquerque, NM 87185, 505-845-9128
}

\begin{abstract}
The use of focused laser beams and fiber optics to control the location and density of current filaments in GaAs photoconductive semiconductor switches (PCSS) is described in this paper. An intensified CCD camera is used to monitor the infrared photoluminescence of the filaments during fast initiation of high gain switching for several sizes of lateral GaAs PCSS (e. g. $0.5 \times 5,1 \times 5,2.5 \times 5,2$ $\times 30$, and $15 \times 20 \mathrm{~mm}^{2}$ ). The switches are triggered with either a focused, mode-locked, Nd:YAG laser (532 and $1064 \mathrm{~nm}$ ) or fiber-optically coupled semiconductor laser diodes $(\sim 900 \mathrm{~nm})$. The dependencies of the size, location, and density of the current filaments on the optical trigger, switch voltage, and switch current will be discussed. The impact of optically controlled current filaments on device design and lifetime is emphasized. Electro-optical switching amplification is demonstrated using the high gain switching mode of GaAs (lock-on). A single semiconductor laser diode is used to trigger a small GaAs PCSS. This PCSS is used to drive a 15element laser diode array. Both electrical and optical pulse compression, sharpening, and amplification are achieved. Estimates for electrical and optical power gains are 8000 and 750 respectively.
\end{abstract}

\section{DISCLAIMER}

This report was prepared as an account of work sponsored by an agency of the United States Government. Neither the United States Government nor any agency thereof, nor any of their employees, makes any warranty, express or implied, or assumes any legal liability or responsi- bility for the accuracy, completeness, or usefulness of any information, apparatus, product, or process disclosed, or represents that its use would not infringe privately owned rights. Reference herein to any specific commercial product, process, or service by trade name, trademark, manufacturer, or otherwise does not necessarily constitute or imply its endorsement, recommendation, or favoring by the United States Government or any agency thereof. The views and opinions of authors expressed herein do not necessarily state or reflect those of the United States Government or any agency thereof.
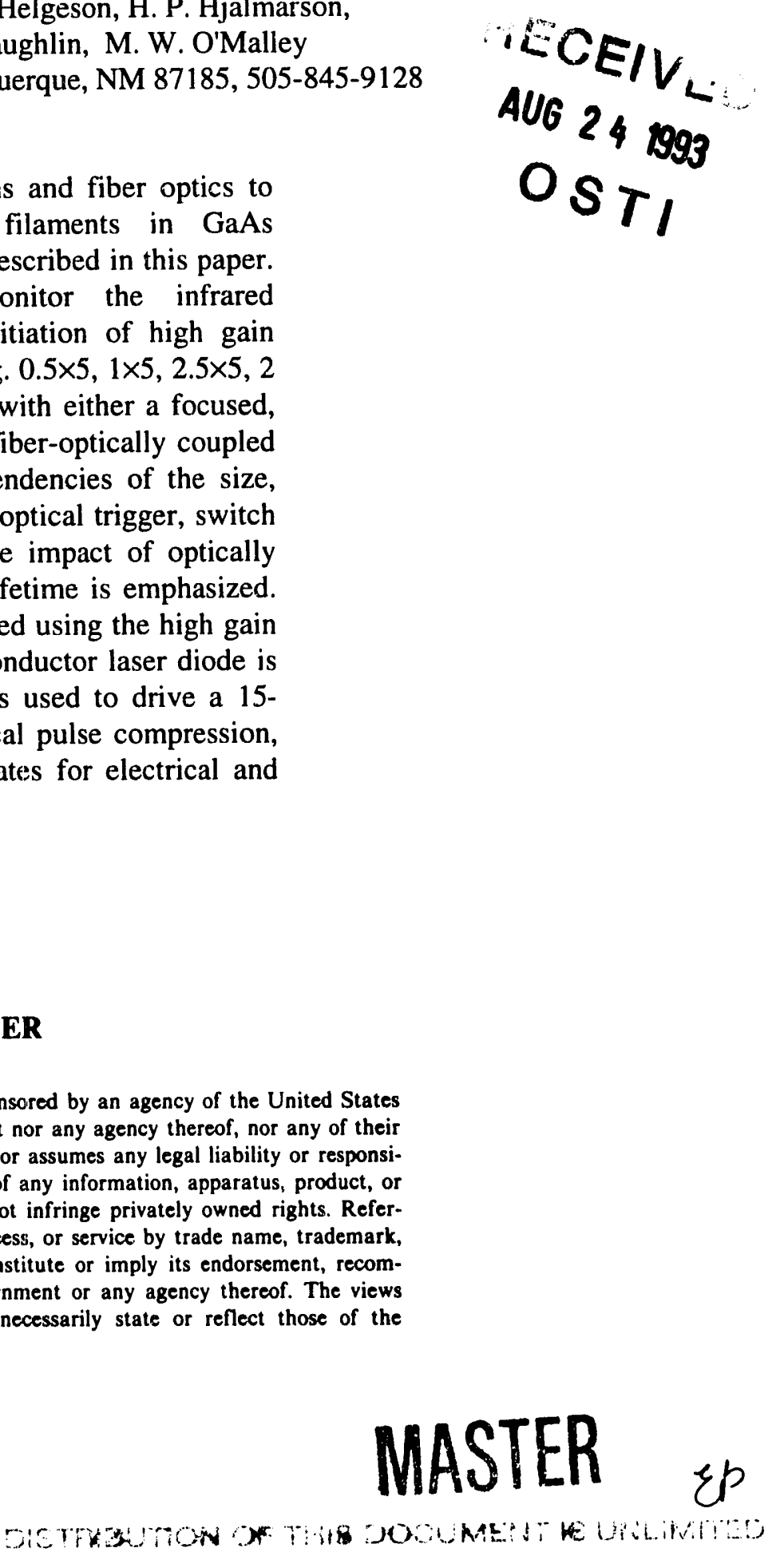

*This work was supported by the U. S. Department of Energy under Contract DE-AC04-76DP00789 


\section{Introduction}

High gain or non-linear switching with GaAs PCSS (sometimes referred to as "lock-on") has been the subject of many papers. ${ }^{1}$ Current filamentation during this switching mode was reported at the last meeting of this conference ${ }^{2,3}$. Photographs of the infra-red $(875 \mathrm{~nm})$ radiation, which is emitted as carriers recombine, provide pictures of the location of high carrier densities during high speed switching. Figure 1 shows an example of an IR image obtained from a $1.5 \times 2 \mathrm{~cm}^{2} \mathrm{GaAs}$ PCSS. This image is rich in structure. It shows a wide range of size and brightness, and it displays branching in both directions. Similar to the images of electrical breakdown in gas, pictures like this one indicate that the current is concentrated into one or more filaments whenever high gain switching is initiated. Increasing the optical trigger energy or the switch current, increases the number, size, and brightness of the filaments. Focused or fiber-optic coupled laser beams have been used to control the location and number of filaments ${ }^{4}$. Concentrating the optical trigger energy near the contacts has also shown increased trigger gain and improved switch longevity ${ }^{5}$. This paper reports on a continued effort to explore and develop the properties of these current filaments for compact, high current switching applications.

\section{Minimum Optical Trigger Energy}

The minimum optical energy which is required to trigger a GaAs PCSS in the high gain switch mode depends on many experimental variables. Properties of lateral switches which affect trigger sensitivity include the insulating gap length and width, carrier recombination time, and switch resistivity. Optical properties which influence triggering include: wavelength, temporal width, spatial size, and uniformity. Electrical properties include the initial field produced across the switch and the circuit configuration. These dependencies have been reported for some of these parameters in a few isolated cases. For example, the minimum optical trigger energies, that have been reported as a function of switch field with $1.5 \times 2 \mathrm{~cm}^{2}$ switches using a $300 \mathrm{ps}$ long, $532 \mathrm{~nm}$, spatially uniform optical trigger, range from 25 to $500 \mu \mathrm{J}^{6}$. When the light was focused to a $1 \mathrm{~mm}$ or smaller spot and concentrated near the contacts of the same type of switch, approximately 100 times less light was required, as low as $500 \mathrm{~nJ}$ at 30 $\mathrm{kV} / \mathrm{cm}^{4}$. On the other hand, recent results with a $10 \mathrm{~ns}$ laser at $880 \mathrm{~nm}$ on $2.5 \times 2.5 \mathrm{~cm}^{2}$ switches show uniform triggering as low as $20 \mathrm{~nJ}$ which increases when the beam is focused to a spot that is smaller than the switch. ${ }^{7}$ The trigger energy dependence on wavelength is complicated by absorption depth, band gap, and reflectivity variations with wavelength, eleetric field, and temperature. The fact, that the minimum optical trigger enery is observed at $880 \mathrm{~nm}$, could imply that the optimum absorption depth for filament initiation is $10-20 \mu \mathrm{m}$, which might correspond to the average size or depth of a filament. 
Some of our results with a fiber-optic coupled laser diode are summarized in Table I. A few results obtained in other experiments are also included for comparison. General trends are decreasing trigger energy with increasing electric field and increasing trigger energy with increasing switch length. However, a more complete study of each parametric dependence is required, before the trigger energy requirement can be predicted for an arbitrary set of parameters.

Table I. GaAs PCSS: Focused Triggering Parameters

\begin{tabular}{|c|c|c|c|c|c|c|c|c|}
\hline \multicolumn{4}{|c|}{ OPTICAL TRIGGER } & \multicolumn{5}{c|}{ SWITCH PARAMETERS } \\
\hline $\begin{array}{c}\text { pulse } \\
\text { energy } \\
(\mu \mathrm{J})\end{array}$ & $\begin{array}{c}\text { pulse } \\
\text { width } \\
(\mathrm{ns})\end{array}$ & $\begin{array}{c}\text { wave- } \\
\text { length } \\
(\mathrm{nm})\end{array}$ & $\begin{array}{c}\text { dia- } \\
\text { meter } \\
(\mathrm{mm})\end{array}$ & $\begin{array}{c}\text { sub- } \\
\text { strate } \\
\text { type }\end{array}$ & $\begin{array}{c}\text { gap } \\
\text { length } \\
(\mathrm{mm})\end{array}$ & $\begin{array}{c}\text { gap } \\
\text { width } \\
(\mathrm{mm})\end{array}$ & $\begin{array}{c}\text { carrier } \\
\text { lifetime } \\
(\mathrm{ns})\end{array}$ & $\begin{array}{c}\text { electric } \\
\text { field } \\
(\mathrm{kV} / \mathrm{cm})\end{array}$ \\
\hline 0.5 & 0.3 & 532 & 1.0 & $\mathrm{Cr}:$ & 15.0 & 20.0 & 1.5 & 30 \\
\hline $2.5 ?$ & 6.0 & 1064 & 0.4 & LEC. & 2.5 & 2.5 & $3.0 ?$ & 40 \\
\hline 0.5 & 20 & 834 & 0.3 & $\mathrm{Cr}:$ & 1.0 & 2.5 & 1.5 & 60 \\
\hline 0.9 & 20 & 834 & 0.3 & LEC & 2.5 & 2.5 & $5.0 ?$ & 90 \\
\hline $10 ?$ & 0.3 & 1064 & 1.0 & $\mathrm{Cr}:$ & 15.0 & 20.0 & 1.5 & 30 \\
\hline 0.9 & 20 & 834 & 0.3 & $\mathrm{Cr}:$ & 2.5 & 5.0 & 1.5 & 90 \\
\hline 0.5 & 20 & 834 & 0.3 & $\mathrm{Cr}:$ & 1.0 & 5.0 & 1.5 & 80 \\
\hline $\mathrm{C.9}$ & 20 & 834 & 0.3 & $\mathrm{Cr}:$ & 1.0 & 5.0 & 1.5 & 50 \\
\hline 0.5 & 20 & 834 & 0.3 & $\mathrm{Cr}:$ & 0.5 & 5.0 & 1.5 & 60 \\
\hline 0.9 & 20 & 834 & 0.3 & $\mathrm{Cr}:$ & 0.5 & 5.0 & 1.5 & 40 \\
\hline 0.5 & 20 & 834 & 0.3 & LEC & 0.5 & 5.0 & 10 & 20 \\
\hline 0.9 & 20 & 834 & 0.3 & LEC & 0.5 & 5.0 & 10 & 12 \\
\hline 0.5 & 20 & 834 & 0.3 & LEC & 1.0 & 5.0 & 10 & 20 \\
\hline 0.9 & 20 & 834 & 0.3 & LEC & 1.0 & 5.0 & 10 & 12 \\
\hline 0.9 & 20 & 834 & 0.3 & LEC & 2.5 & 5.0 & 10 & 90 \\
\hline
\end{tabular}

$\mathrm{Cr}:=$ Chrome-doped GaAs

LEC $=$ liquid encapsulated Czochralski GaAs

\section{Filament Size}

An upper limit for the diameter of current filaments can be obtained from the photo-luminescence images. Figures 2 and 3 show an image which has been analyzed to estimate the width of the brightest current filaments: $150-250 \mu \mathrm{m}$. Significantly smaller filaments are also observed. These numbers probably represent upper limits for several reasons: (1) the bright filaments may actually be unresolved groups of filaments, (2) bright emitters against dark backgrounds typically look larger than they are, and (3) the infrared radiation is strongly absorbed and reemitted by regions of the semiconductor near the filament causing spatial broadening.

A lower limit of filament widths, is provided by measurements of switch damage, which has been observed near the contacts: $1-10 \mu \mathrm{m} .{ }^{8}$ These numbers are probably under-estimates, since they represent only the "hottest" regions of the filaments and they may be dependent upon the contact interface to the semiconductor. 
The IR photoluminescence images are strongly influenced by self-absorption of the emitted radiation. In addition to the spatial broadening already mentioned, the filaments are probably only visible down to about $10 \mu \mathrm{m}$. Some filaments, such as the one in figure 4, appear to end abruptly in the middle of the switch extending to the other contact. The abrupt branching of the filaments which we can observe near the surface suggests that rather than "ending", such filaments probably branched deeper into the semiconductor and were no longer visible. However, it is also possible that the current suddenly became so diffuse that a bright filament was no longer observed.

\section{Filamentation at High Currents}

Our previously reported images of current filaments were taken with switches which were conducting at most a few hundred amps. Since we are also pursuing applications which need many kiloamps, and have switched as high as $4 \mathrm{kA}$ with a single $2 \times 30 \mathrm{~mm}^{2} \mathrm{GaAs}$ PCSS, the characteristics of filaments at higher currents were of prime interest. Figure 5 shows filaments that were observed near the threshold for triggering with uniform illumination in a sequence of tests ranging from 120 to $1800 \mathrm{~A}$. These tests were similar to our previous high current tests, which we performed before we realized that the current was filamentary. In these new images, the intensity and size of the filament groups increased with increasing current. The filaments were strongly concentrated in one or two regions of the switch. The current density would be reduced significantly, if this current could be spread out by inducing more filaments over the entire width of the switch. Increased optical trigger intensity, or more efficient use of the optical trigger by concentrating it near the contacts, might be a key to reducing switch degradation and increasing device longevity.

In addition to the infra-red emission from the insulating region of the semiconductor, bright spots began to appear from the metal contacts near the ends of the filaments. These were clearly visible to the naked eye at higher currents. These regions of the contacts also showed discoloration and changes in the surface texture following switching. Figure 6 shows a view of a region of a switch which passed $2.4 \mathrm{kA}$. If the emission from the metal contacts is thermal, then the temperature in this region must be greater than $800 \mathrm{~K}$ where the tail of the black body radiation spectrum starts to have a significant portion in the visible. If it is not thermal, then it may be evidence of some field ionization that is occurring in the damaged region of the contact or above the metal in the liquid dielectric (Fluorinert). 
The energy dissipated in this region of the switch originates from at least two sources. Assume there is a $1 \mathrm{~V}$ barrier to injection at the metal semi-conductor interface. Then at $2.4 \mathrm{kA}, 120 \mu \mathrm{J}$ is accumulated in $50 \mathrm{~ns}$. Uniform distribution of this energy in the bright region of the metal contact layer would increase the temperature by only $20 \mathrm{C}(2 \mathrm{~mm} \times 2 \mathrm{~mm} \times 0.8 \mu$ $\mathrm{m})$. Another possibility is the resistive loss in the thin gold contact. At room temperature the resistance of this region to lateral current flow is about $40 \mathrm{~m} \Omega$. The voltage drop across this region at $2.4 \mathrm{kA}$ would be about $100 \mathrm{~V}$. Thus, the energy dissipated is $12 \mathrm{~mJ}$, and the temperature rise would be $2000 \mathrm{C}$. While these estimates are only crude approximations, they indicate that resistive heating in the contact metallization is probably the cause of the glow.

Contacts with thicker metallization $(8.0 \mu \mathrm{m})$ have been fabricated to test this hypothesis by reducing their resistance. (The skin depth of gold in this time regime is approximately $20 \mu \mathrm{m}$.) Although a comparison of the light emission has not yet been made, preliminary tests with such contacts show a stronger tendency to separate from the semiconductor after a high current pulse. This may lead us back to a potential barrier at the interface where energy is dissipated over a much thinner region than the thickness of the metallization.

\section{Fiber-optic Coupling}

By concentrating the optical trigger near the switch contacts, we have demonstrated increased optical trigger gain and control of the location and number of current filaments. This result has led us to explore the problems of coupling a semiconductor laser diode array (LDA) to the GaAs PCSS with fiber optics. We started with a single laser diode driven by a high voltage avalanche transistor, a fiber optic pigtail, and a small $0.5 \times 5$ $\mathrm{mm}^{2}$ switch. Then we configured what we call an electro-optical switching amplifier (EOSA). The purpose of the EOSA was to produce one complete stage of electrical and optical amplification using multiple GaAs PCSSs and LDAs. The small, low power, PCSS, which was triggered by a single laser diode, was used to power a small LDA. Then, the LDA could be used to trigger a larger, high power PCSS. The configuration is illustrated in figure 7. This "cascaded amplifier" can be continued to provide fast electrical or optical pulses of increased intensity at each stage. The properties of high gain PCSS sharpen and amplify the pulses, so this scheme could potentially be used to produce arbitrarily large electrical or optical pulses with sub-nanosecond rise times. 
LDA are very low impedance loads, so the small, low inductance PCSS seemed to be the ideal switch for pulsing them rapidly with a low impedance transmission line. After fabricating and testing the low power PCSS and its single laser diode driver, a 15 element LDA was soldered directly to the PCSS contacts. Instead of just producing a fast rising rectangular optical pulse with a width corresponding to the short transmission line, the LDA produces a spike which settles to a lower value (figure 8). The PCSS apparently pumps the LDA so hard that a 6:1 (estimated) population inversion is attained before the micro-cavities start to lase, which should be a few hundred pico-seconds (based upon their 300 $\mu \mathrm{m}$ cavity length). This effect is called gain switching. It is commonly seen in longer cavity (table top) lasers and in single laser diodes where part of the lasing medium is switched rapidly after the rest of the medium has been pumped. Our lowest estimate for the peak optical power is $35 \mathrm{~kW}$, an order of magnitude higher than has been reported for any LDA. A crude estimate of the width of this spike is $50 \mathrm{ps}$ after deconvoluting the bandwidth of the photo-diode and transient digitizer used to record the optical output. Plans have been made to measure this more accurately.

A single fiber optic and fast photo-diode was used to observe the output from each element in the array. Figure 9 shows a comparison of these outputs. Timing jitter was about $50 \mathrm{ps}$ and amplitude variation was approximately $20 \%$. There was systematic trend in timing with the lasers which as yet is unexplained. Lasing was initiated on one side of the array and the rest of the lasers followed consistently and nearly in sequence from that side to the other. This timing sequence could be adjusted to superimpose all of the outputs by using fiber optics with the appropriate optical path lengths.

The EOSA appears to be a very compact and inexpensive way to produce stable, high-power, sub-nanosecond optical or electrical pulses. This system demonstrated an electrical power gain of approximately 8000 , and a conservative estimate for optical power gain of 750. The output of this LDA is now being coupled with individual fibers to trigger multiple filaments on a larger GaAs PCSS.

\section{Conclusion}

This paper has presented some of the recently recorded properties of high gain switching of GaAs PCSS. The minimum energy required to trigger this switching mode is a function of many parameters, which were tabulated for several isolated cases. Estimates ranging from 10-250 $\mu \mathrm{m}$ were made of filament diameters from the infrared images of the recombination radiation and from damage near the contacts. Images of filaments are shown as a function of increasing current up to $2.4 \mathrm{kA}$. The gain of this switching mode was demonstrated in an electro-optical switching amplifier which has practical implications for any application requiring sub-nanosecond, high-power, electrical or optical pulses. 


\section{Figure Captions}

Figure 1. An infra-red image of a GaAs PCSS shows the recombination radiation which is emitted during high gain switching. This mode of "controlled" breakdown is often called "lock-on." It has been used to produce extremely sensitive, optically activated, high power switches.

Figure 2. This IR image was analyzed to set an upper limit on the width of the brightest filaments.

Figure 3. These intensity profiles were obtained from the previous image. After taking into account the direction of the filament relative to the profile, values of $150-250 \mu \mathrm{m}$ were obtained for the full widths at half the intensity maxima.

Figure 4. This IR image shows a filament which apparently "stops" in the middle of the switch. Either the filament made a sudden branch deeper into the switch, where it would no longer be visible, or the current suddenly became too diffuse to produce a bright line image.

Figure 5. This series of photographs shows the changes in current filamentation as current is increased. In each photo, the central dark region is the normally insulating semiconductor. The gray regions bordering the semiconductor are metallic contacts. This area is surrounded by a white wax which contains a liquid dielectric (Fluorinert). Photo (A) is $0.5 \times 5 \mathrm{~mm}^{2}$ and the rest are $1 \times 5 \mathrm{~mm}^{2}$. Initial voltage and peak current are: (A) $1 \mathrm{kV}, 120 \mathrm{~A}$; (B) $5 \mathrm{kV}, 600 \mathrm{~A}$; (C) $7.6 \mathrm{kV} 1300 \mathrm{~A}$, (D) $10 \mathrm{kV} 1800 \mathrm{~A}$.

Figure 6. This photograph shows contact damage produced after this $1 \times 5 \mathrm{~mm}$ switch was conducting $2.4 \mathrm{kA}$ for approximately $50 \mathrm{~ns}$. These contacts, which were previously smooth, became rough and discolored during this test.

Figure 7. The electro-optical switching amplifier (EOSA) that is being developed uses a miniature PCSS to drive the laser diode array (LDA). The properties of high gain GaAs PCSS sharpen and amplify the optical output which can be used to driver larger GaAs PCSS.

Figure 8. The optical signal from one element of the LDA shown in the previous figure. This spike is produced by pumping the laser faster than lasing can be initiated. The measurement was limited by our diagnostic bandwidth of $2.5 \mathrm{GHz}$.

Figure 9. The optical signals from each element in the LDA are shown for timing and amplitude comparison. Each curve was produced by positioning a fiber optic in front of one of the lasers and recording its output signal with a fast photo-diode and a $4.5 \mathrm{GHz}$ transient digitizer. 
1 See proceedings from: 6-8th IEEE Pulsed Power Conf., 1987, 1989, 1991; $18-$ 20th IEEE Power Modulator Symp., 1988, 1990, 1992; SPIE Optically Activated Switching I-III, (vol. 1378, 1632, 1873), 1990, 1992, 1993; and special issues in IEEE Trans. Elec. Devices, (vol. 37,38), 1990, 1991.

2 F. J. Zutavern, G. M. Loubriel, M. W. O'Malley, W. D. Helgeson, and D. L. McLaughlin, "High Gain Photoconductive Semiconductor Switching," in Proc. 8th IEEE Pulsed Power Conf., San Diego, CA, 1991, pp 23-28.

3 R. A. Falk, J. C. Adams, and G. L. Bohnhoff-Hlavlacek, "Optical Probe Techniques for Avalanching Photoconductors" in Proc. 8th IEEE Pulsed Power Conference, San Diego, CA, 1991, pp 29-36.

4 F. J Zutavern, G. M. Loubriel, M. W. O'Malley, W. D. Helgeson, D. L. McLaughlin, and G. J. Denison, "Characteristics of Current Filamentation in High Gain Photoconductive Semiconductor Switching," in Proc. 20th IEEE Power Modulator Symposium, Myrtle Beach, SC, 1992, pp 305-311.

5 F. J. Zutavern, G. M. Loubriel, D. L. McLaughlin, M. W. O'Malley, W. D. Helgeson, and G. J. Denison, "GaAs PCSS: High Gain Switching and Device Reliability," to be published in Proc. SPIE Optically Activated Switching III (vol. 1873), Los Angeles, 1993.

6 V. B. Carboni, I. D. Smith, R. M. Pixton, M. D. Abdalla, F. J. Zutavern, G. M. Loubriel, M. W. O'Malley, "Tests on Photoconductive Semiconductor Switches for Subnanosecond Rise Time, Multimegavolt Pulser Applications," in Proc. 8th IEEE Pulsed Power Conference, San Diego, CA, 1991, pp 109113.

7 Choy et. al, to be published in Proc. 9th IEEE Pulsed Power Conference, Albuquerque, NM, 1993.

8 A. G. Baca, H. P. Hjalmarson, G. M. Loubriel, D. L. McLaughin, and F. J. Zutavern, "High Current Density Contacts for Photoconductive Semiconductor Switches," to be published in Proc. 9th IEEE Pulsed Power Conference, Albuquerque, NM, 1993. 


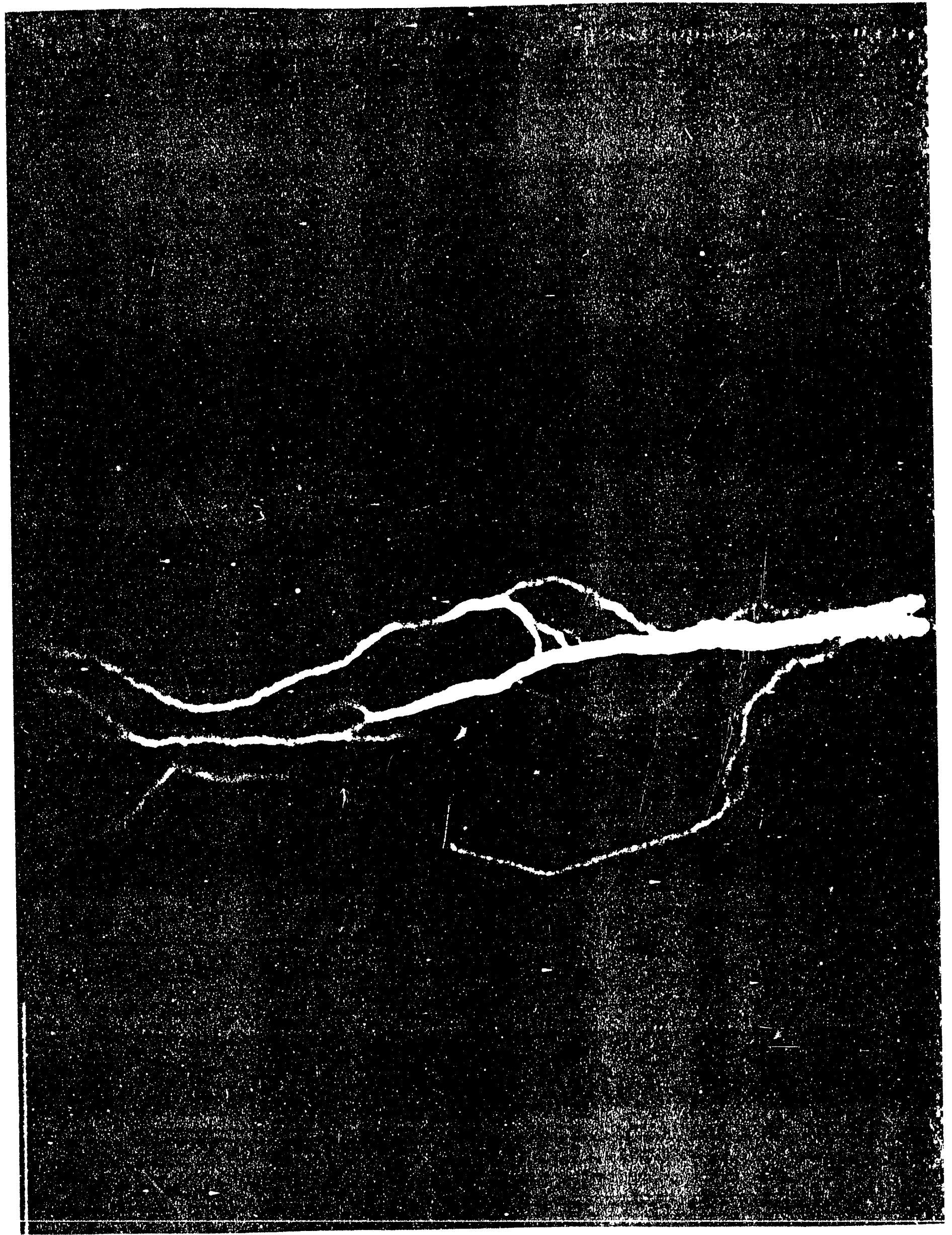




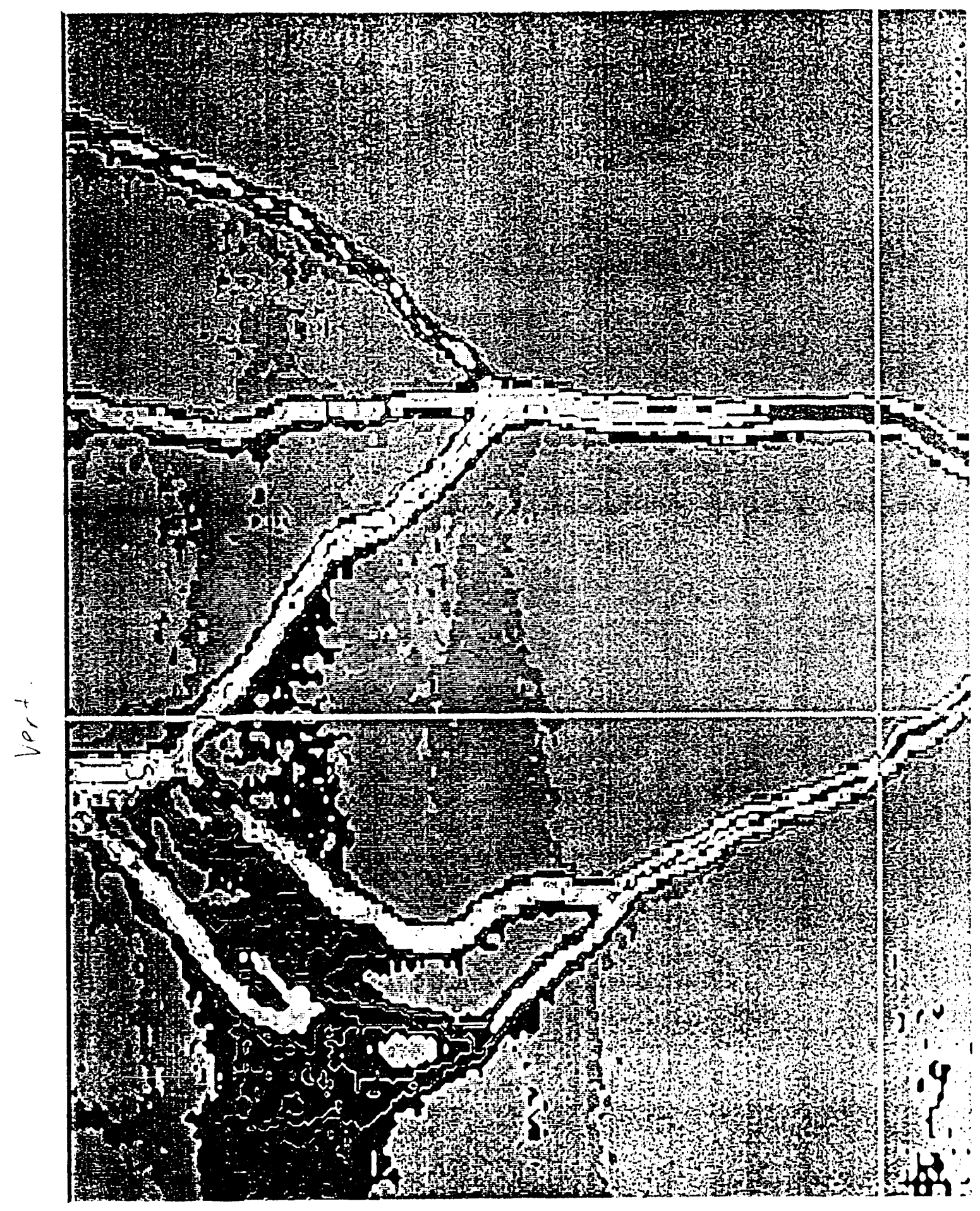




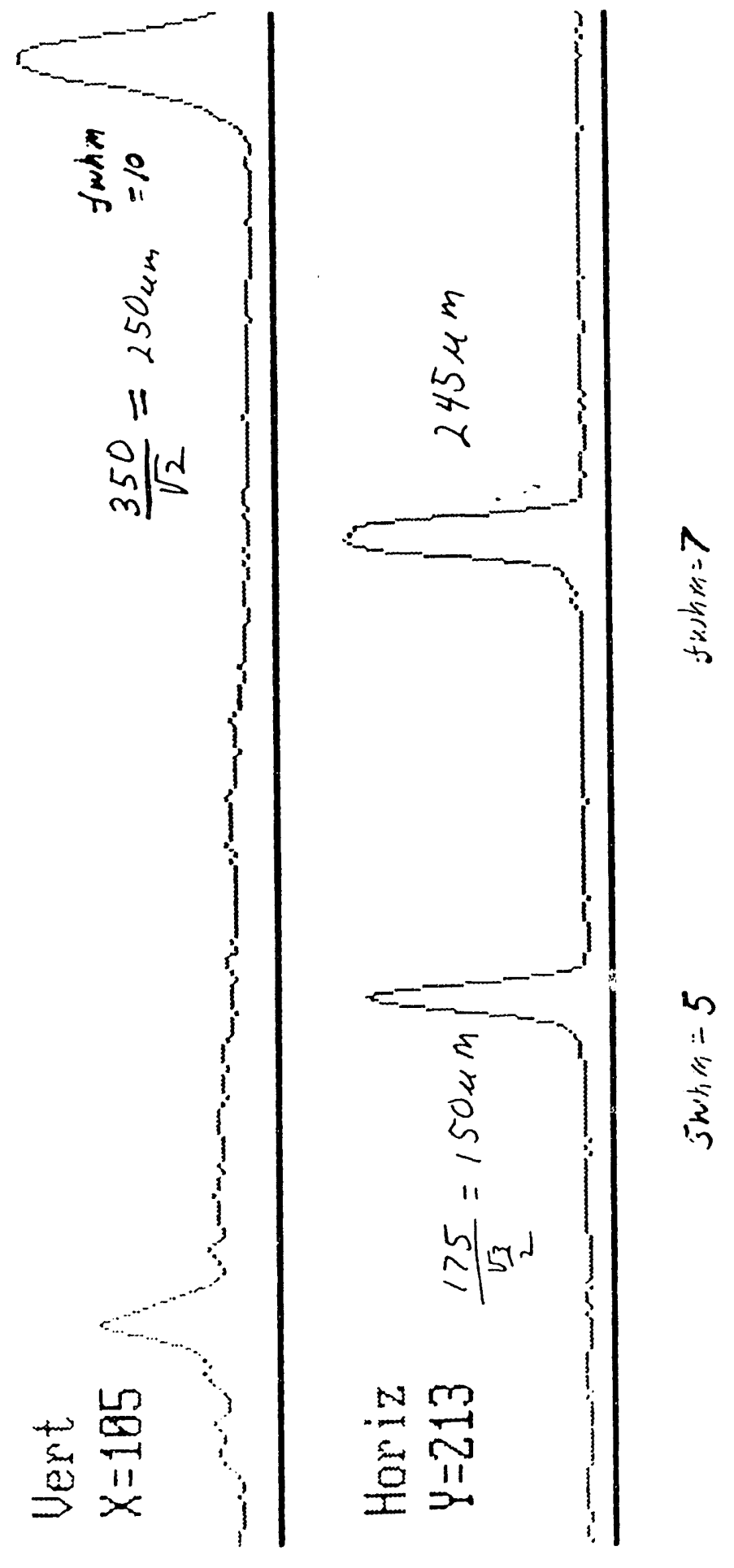

in 


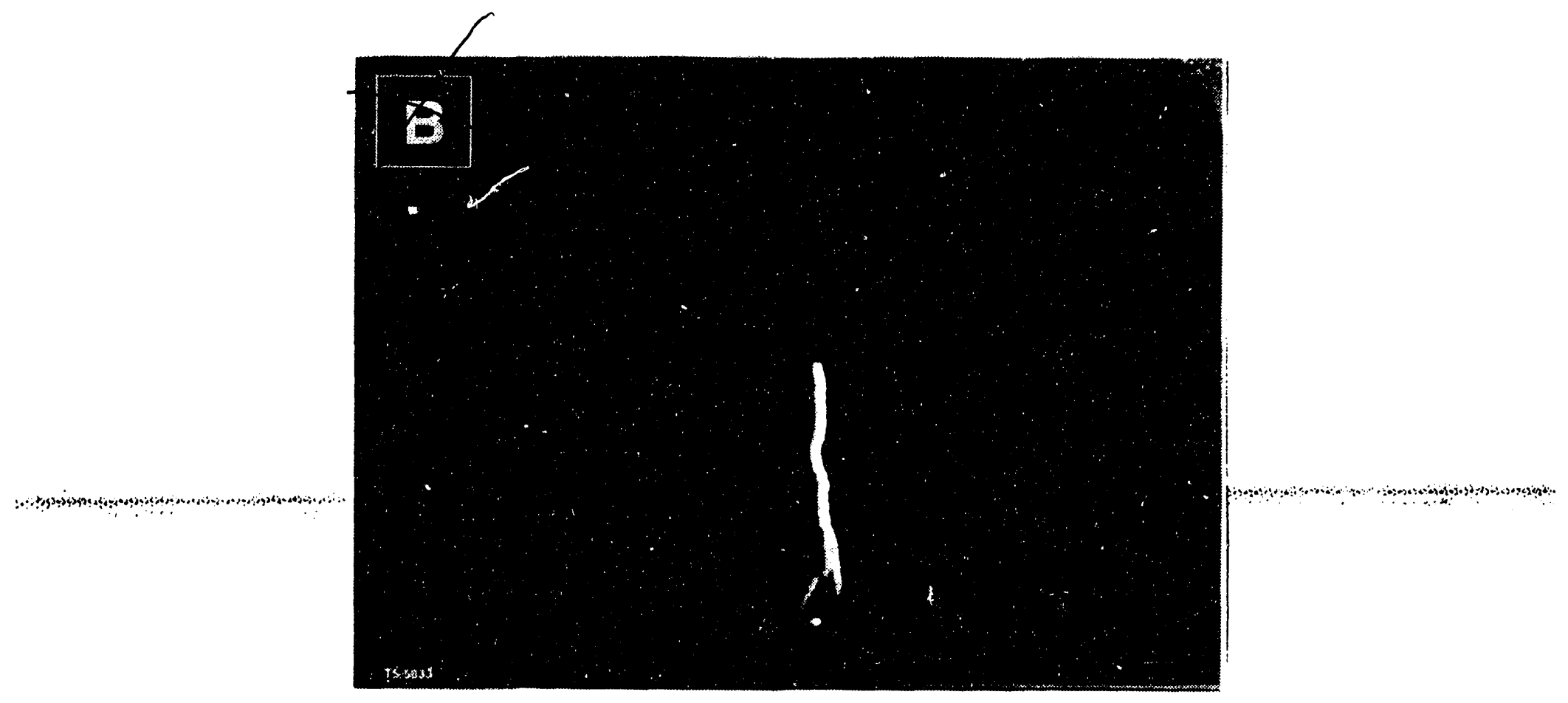

Figure 4 

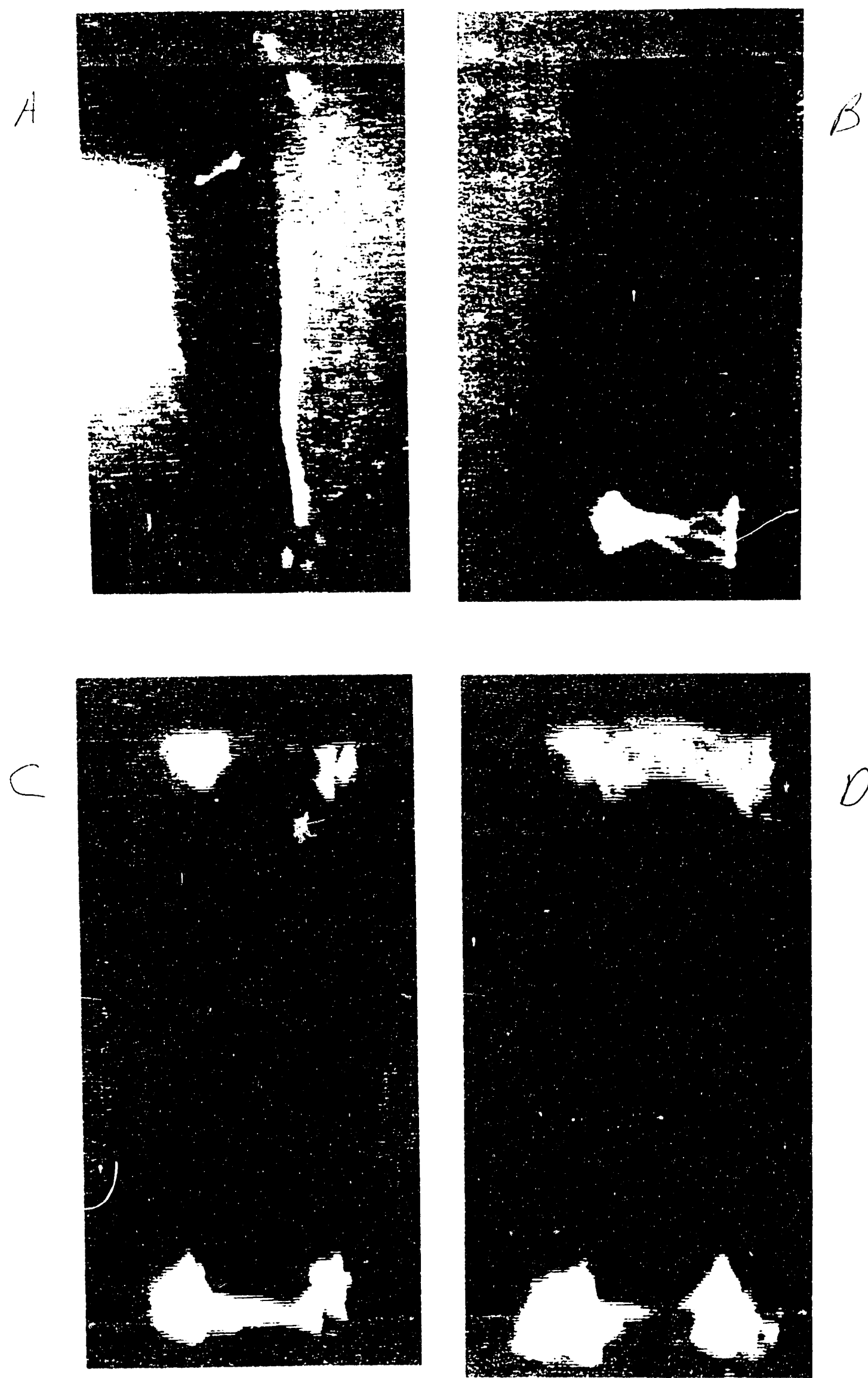

$D$

$$
\text { inchi } 5
$$




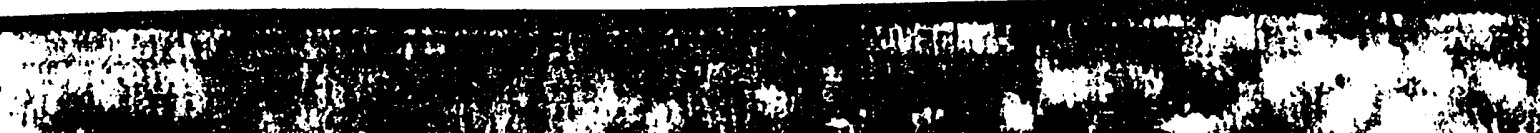
-

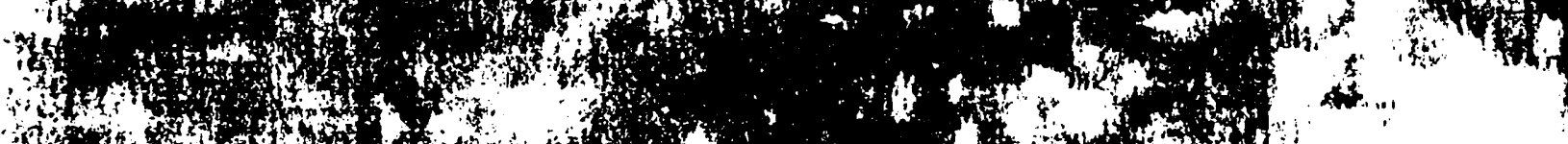

-

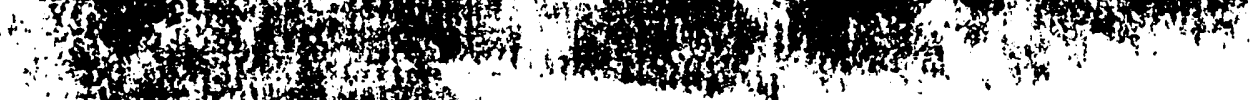

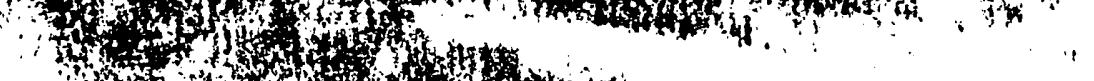

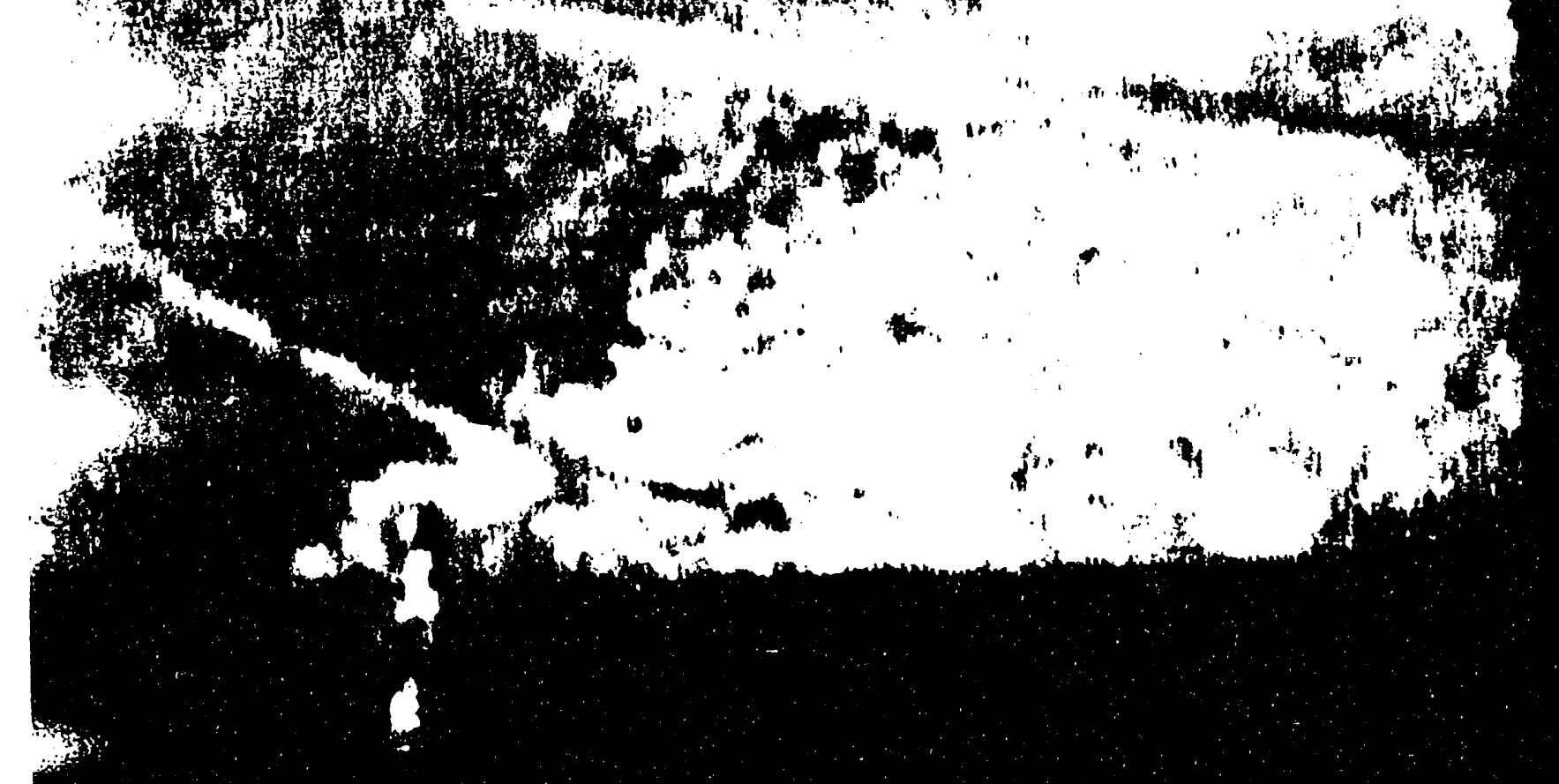

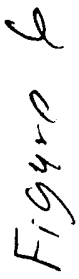

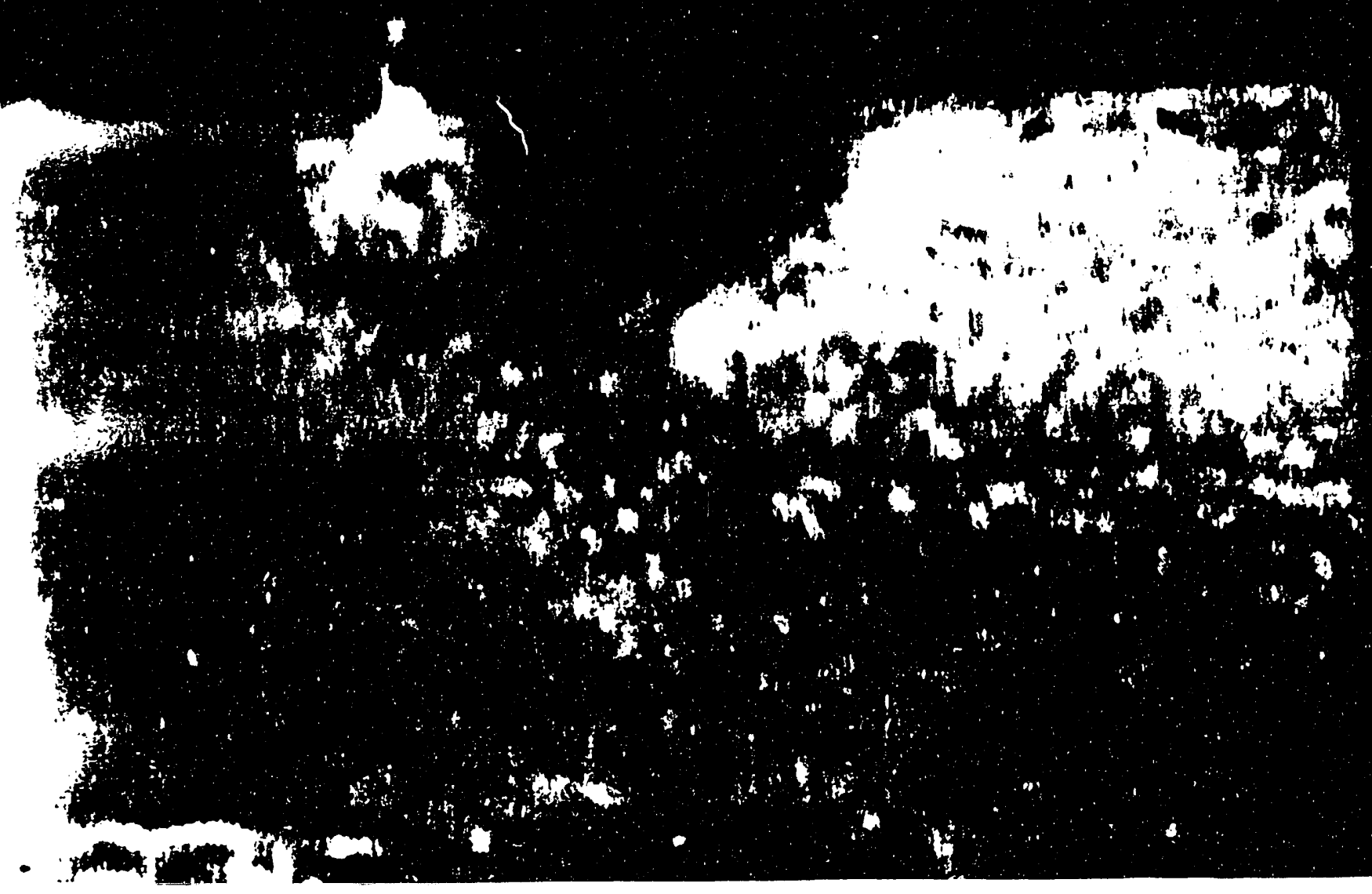

s 


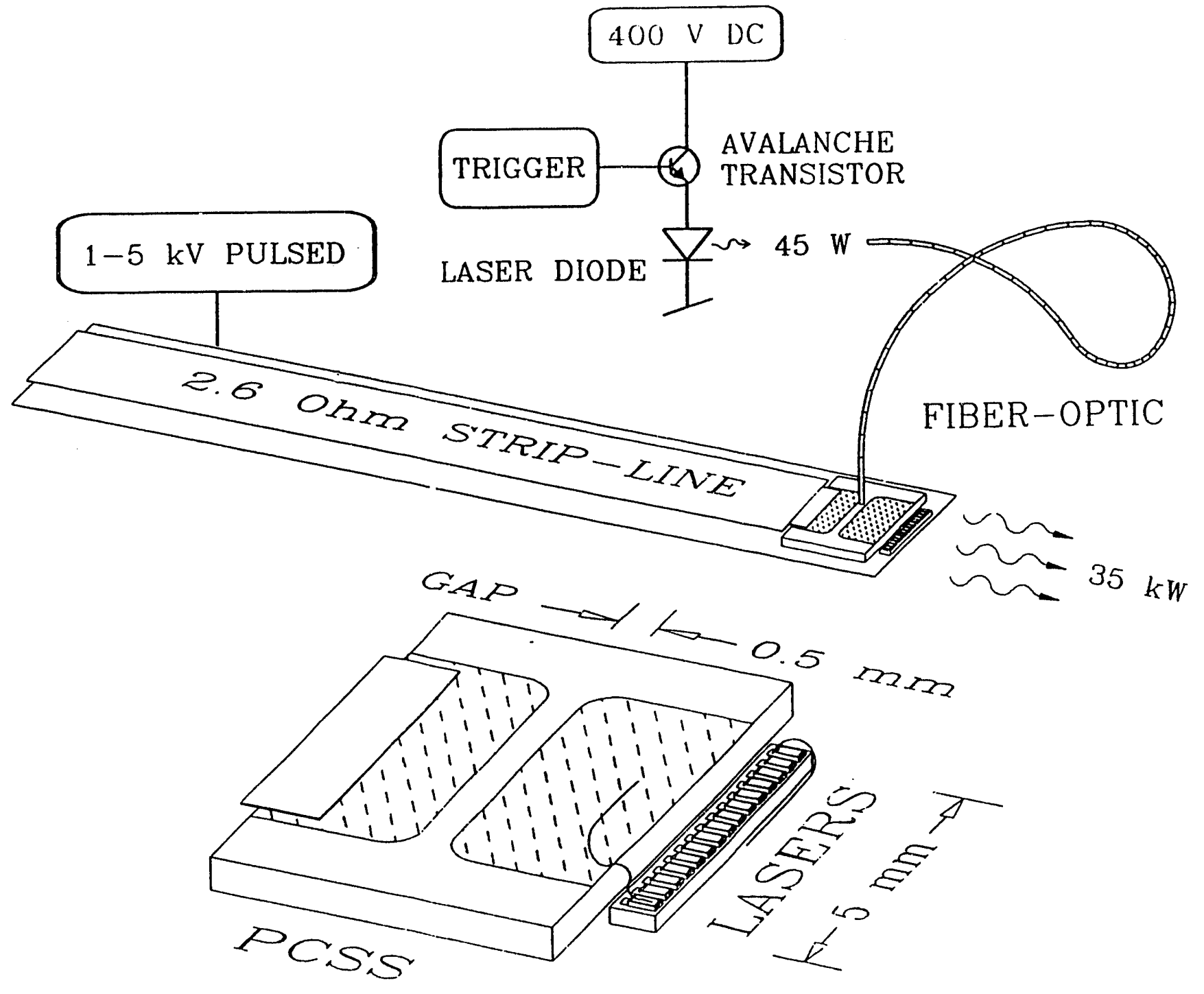

Figure 7 

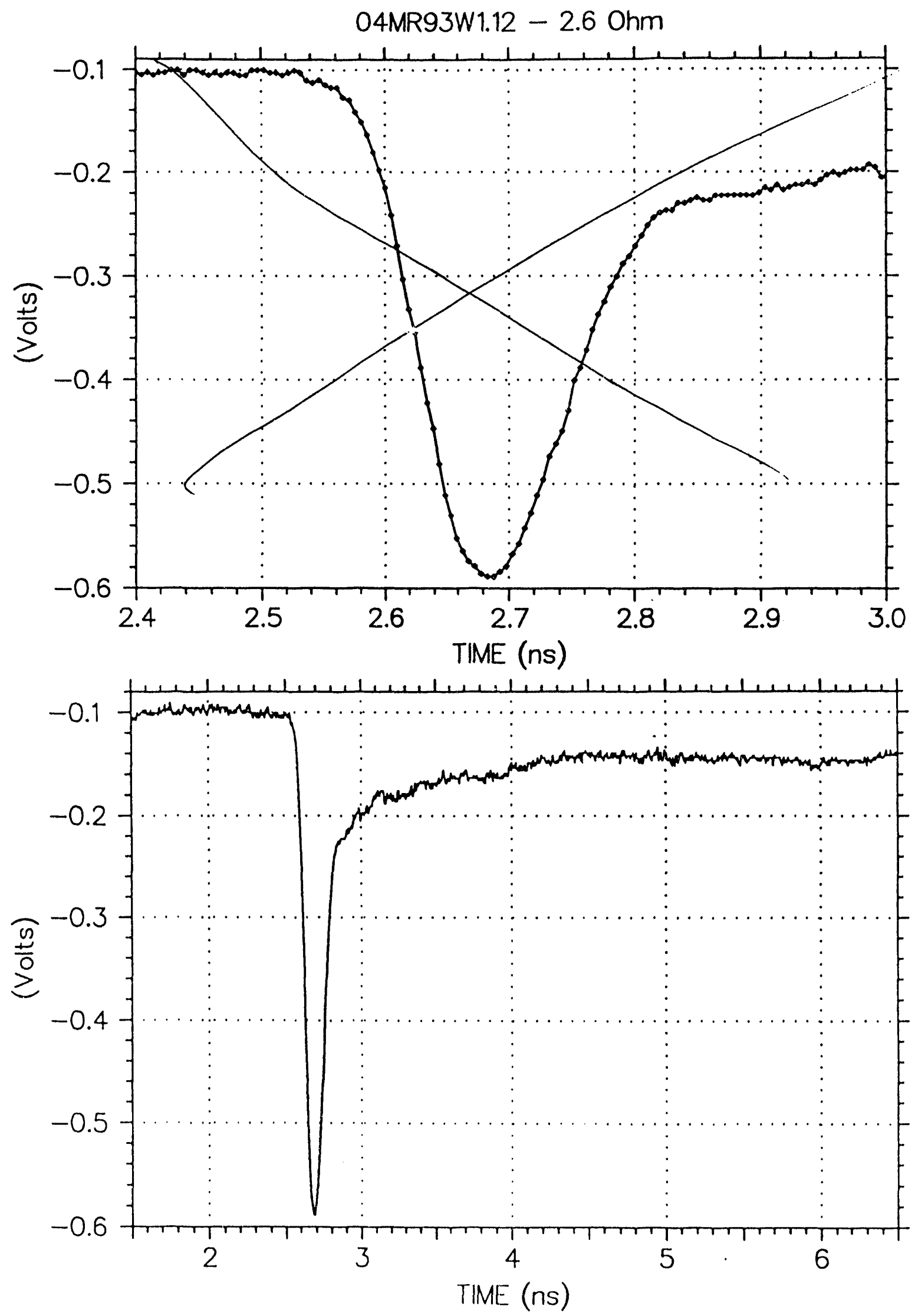

Figure 8 


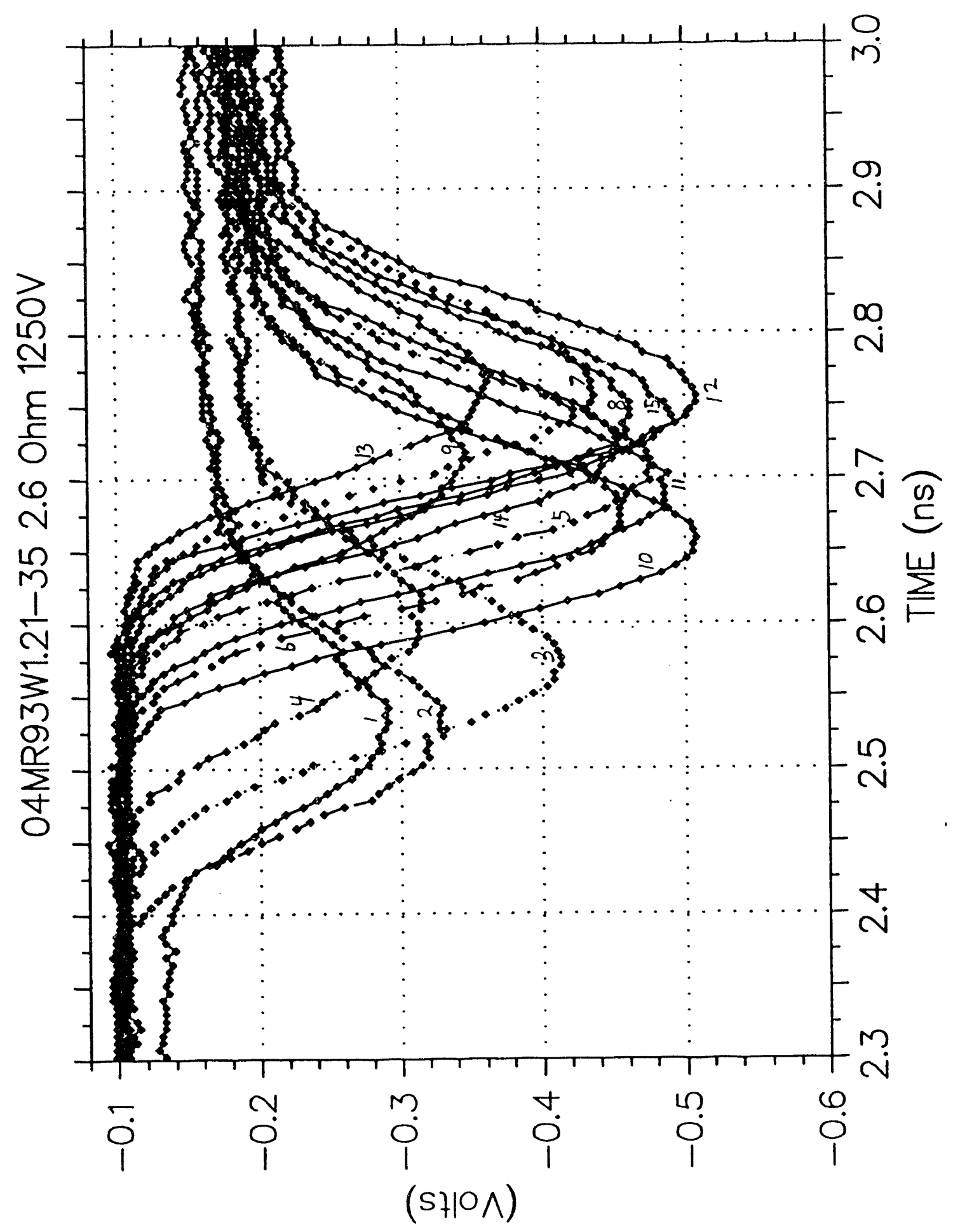



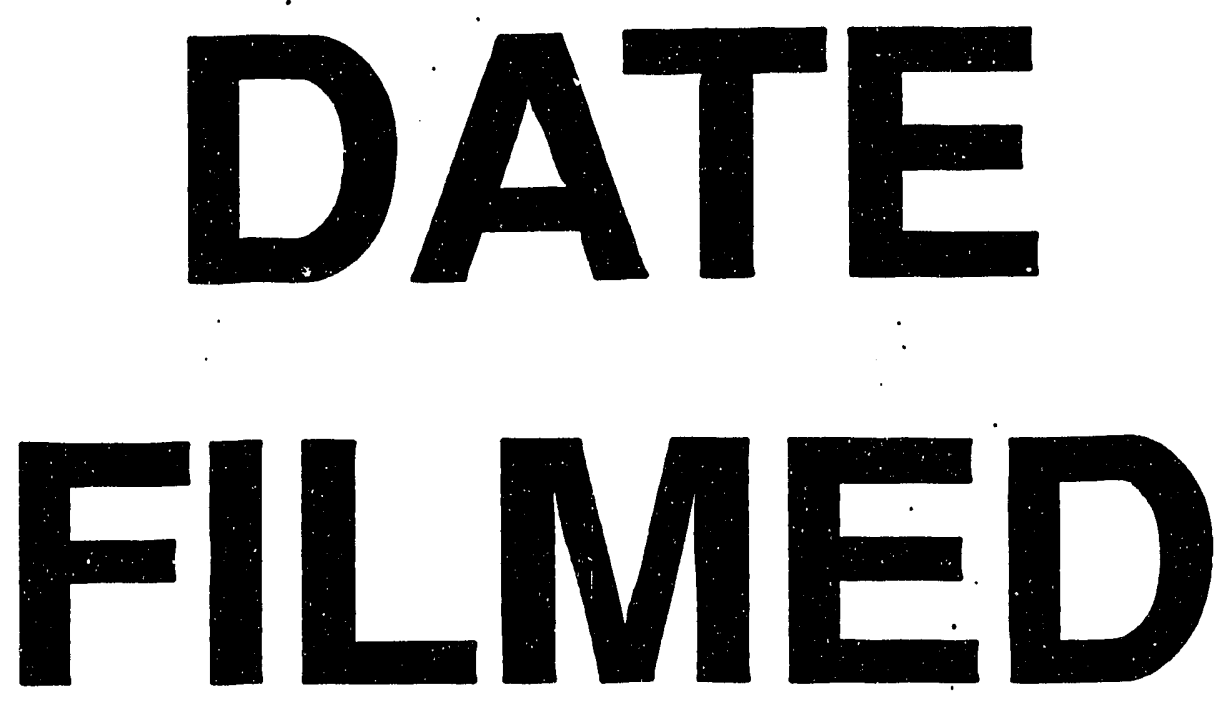

$10 / 25 / 93$
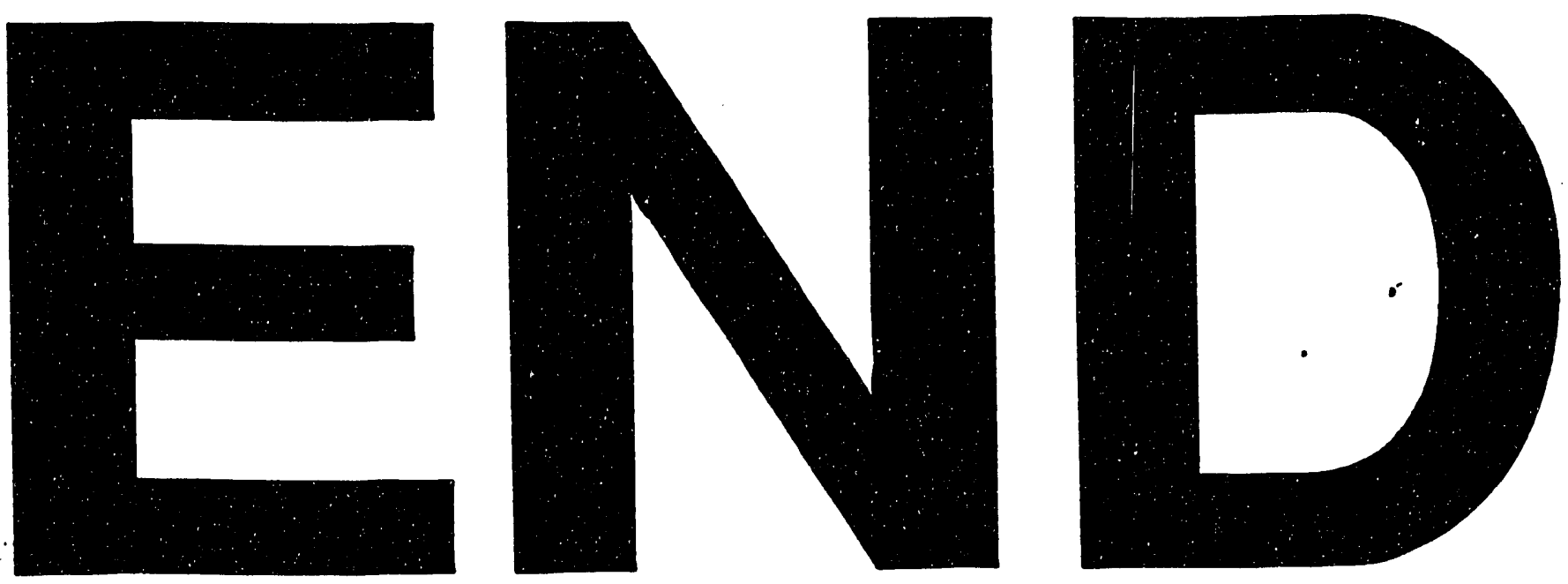
